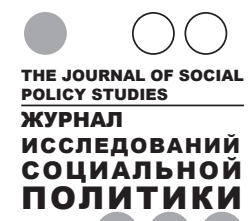

Владимир Смирнов

\title{
РЕГИОНАЛЬНЫЕ СИСТЕМЫ СОЦИАЛЬНОГО ПРЕДПРИНИМАТЕЛЬСТВА В РОССИИ: ТИПОЛОГИЯ, ФАКТОРЫ РАЗВИТИЯ, КЛЮЧЕВЫЕ ПРОТИВОРЕЧИЯ
}

\begin{abstract}
В России в последнее десятилетие актуализируется дискуссия вокруг социального предпринимательства, основу которой составляет проблематика более эффективного (по сравнению с бюджетными организациями) решения социальных проблем. Основными акторами, которые претендуют на статус социального предпринимателя, выступают социально ориентированные некоммерческие организации и субъекты малого и среднего бизнеса. В российских регионах формируется три механизма институциализации социального предпринимательства. Первый связан с развитием системы социальных инвестиций как со стороны государства, так и со стороны крупного бизнеса. Второй- с попыткой российского правительства включить негосударственные организации в систему государственной социальной политики через участие в предоставлении социальных услуг населению. Третий- с нормативным закреплением статуса социального предприятия. Ими должны стать субъекты малого и среднего бизнеса, реализующие социальную миссию. В статье анализируются особенности реализации двух первых механизмов в российских регионах. Важность рассмотрения социального предпринимательства через региональную призму связана с тем, что сегодня российские регионы развиваются неравномерно. В качестве информационной базы исследования автор использует собранные им данные, характеризующие систему государственных и негосударственных социальных инвестиций в России, а также региональные реестры поставщиков социальных услуг. На основе кластерного анализа осуществляется типология российских регионов с точки зрения развитости региональных социально-предпринимательских систем. Делается вывод о конкуренции социально ориентированных некоммерческих организаций и субъектов малого и среднего
\end{abstract}

Владимир Алексеевич Смирнов- д.социол.н., доцент, проректор по стратегическим коммуникациям, Костромской государственный университет, Кострома, Россия. Электронная почта: kano_igt@mail.ru 
бизнеса на рынке социально-предпринимательских услуг. Развитие социально-предпринимательских практик в российских регионах характеризуется как низкое, выделяются три фактора, влияющих на такое положение дел: социально-экономическое развитие конкретного региона, уровень социальных инвестиций, наличие и эффективность институтов поддержки социального предпринимательства (таких как центры инноваций социальной сферы). Выявлен ряд непреднамеренных последствий государственной политики в России, которые тормозят развитие социального предпринимательства. Наиболее значимыми из них являются: укрепление межсекторных границ между некоммерческим сектором и бизнес-сообществом, снижение мотивации предпринимателей для развития социально-предпринимательских практик, доминирование бюджетных организаций на рынке социальных услуг.

Ключевые слова: социальное предпринимательство, СОНКО, малый и средний бизнес, поставщики социальных услуг

DOI: 10.17323/727-0634-2021-19-1-23-40

Сегодня можно говорить о формировании двух парадигм, по-разному определяющих феномен социального предпринимательства (Dees 1998; Bacq, Janssen 2011). Первая связана с понятием социальных инноваций и определяет социальное предпринимательство как инновационную деятельность по решению социальных проблем (Chell 2007; Simms, Robinson 2008; Anderson, Dees 2008). Вторая рассматривает социальное предпринимательство как бизнес с выраженной социальной миссией, в которую реинвестируется прибыль предприятия (Nicholls 2008). Речь идет об особой организационно-правовой форме бизнеса, не обязательно ориентированной на инновационные решения. Большое число исследователей склоняется к первой парадигме, рассматривая социальное предпринимательство как широкое межсекторное, гибридное явление, где на первое место выходит как социальный, так и экономический результат (Кикал 2014).

Социальное предпринимательство в России проходит стадию становления, поэтому значительное число исследований посвящено осмыслению этого процесса (Сакоян 2012; Албутова 2013). При этом важно, что российские исследователи в большинстве своем также придерживаются «широкой» парадигмы (Баталина и др. 2007; Баханькова и др. 2013; Якимец, Никовская 2019). Целый ряд работ посвящен изучению мотивации и поведения российских социальных предпринимателей (ЦИРКОН 2013; Недялкова 2016), их типологии (Арай 2018), региональным особенностям социального предпринимательства (Суслова 2014; Якимец, Никовская 2019). В статье рассматривается становление социального предпринимательства в региональном разрезе, особенности взаимодействия основных акторов, выделяются группы регионов с разным уровнем развития экосистем социального предпринимательства. 


\section{Информационная база и методы исследования}

В основу исследования положены несколько информационных баз: список победителей (190 записей) конкурса социальных предпринимателей Фонда региональных социальных программ «Наше будущее» (Проекты ФНБ 2020); перечень (432 записи) социальных предприятий, включенных в реестр ФНБ (Новый бизнес 2020); проекты социально ориентированных некоммерческих организаций- СОНКО (52820 записи), участвовавших во всех конкурсах президентских грантов за период с 2017 по 2020 г. (Проекты ФПГ 2020); база данных российских регионов (80 записей), содержащая информацию об общем количестве СОНКО и субъектов малого и среднего предпринимательства (МСП), входящих в реестры поставщиков социальных услуг. Информация из всех баз данных была агрегирована по регионам. Учитывая, что не все регионы представлены в каждой информационной базе, строки с пропущенными значениями были удалены из массива. Агрегированная база данных включает 39 регионов, характеризующихся 17 признаками. Все данные, а также программный код (на языках $R$ и Python) по их преобразованию и анализу размещены в открытом доступе, в соответствии с идеологией воспроизводимых исследований (Github 2020).

Методологическую основу статьи составляют сравнительный и типологический методы. Для проверки и обоснования теоретических выводов использованы факторный и кластерный анализ, для оценки статистической значимости различий между двумя и более группами-непараметрические тесты Манна-Уитни и Краскела-Уоллиса (выбор непараметрических методов связан с небольшим объемом выборки и невозможностью сделать выводы о нормальном характере распределения данных).

\section{Механизмы формирования региональных систем социального предпринимательства}

Анализ международного опыта развития социального предпринимательства позволяет выделить два механизма формирования субъектов социального предпринимательства. Первый- социальные инвестиции. Мировым лидером здесь является Фонд Ашока (Борнштейн 2012), который инвестирует в проекты социальных инноваторов по всему миру уже почти 30 лет. Инвестиции становятся фактором появления новых социальных технологий, эффективных проектов, способных к трансформации в экономически устойчивые социальные предприятия. В США и некоторых Европейских странах такие практики развиваются многие десятилетия (OECD 2015). Россия находится лишь в начале пути формирования среды для социальных инвестиций. Тем не менее 13-летний опыт реализации конкурса проектов социальных предпринимателей, реализуемый ФНБ, 
социальные программы крупных российских бизнес-корпораций, грантовая государственная поддержка российских СОНКО- все это элементы формирующейся системы социальных инвестиций.

Второй механизм - создание гибридных специализированных предприятий, наделенных государством особым статусом, таких, например, как социальные кооперативы в Италии, компании в интересах местного сообщества в Великобритании, компании социального назначения в Бельгии, кооперативы социальной солидарности в Португалии (Bacq, Janssen 2011). Принятие Федерального закона № 245-Ф3- это реализация данного трека в России (Федеральный закон 2019). В нашей стране существует еще один механизм развития социально-предпринимательского сектора-вовлечение СОНКО и субъектов МСП в процесс реализации государственной социальной политики. Важнейшим этапом для его запуска стало принятие закона (Федеральный закон 2013), который позволил СОНКО, а также субъектам МСП стать полноценными участниками рынка социальных услуг.

\section{Социальные инвестиции: возможности и противоречия}

Проанализируем механизмы развития социального предпринимательства применительно к российским регионам. Рассмотрим в качестве субъектов социальных инвестиций ФНБ, выдающий займы социальным предприятиям, и ФПГ, оказывающий грантовую поддержку российским СОНКО. За период с 2007 г. победителями ФНБ стали около 200 человек из 54 регионов России, при этом за последние 4 года гранты ФПГ получили более 11 тыс. СОНКО из 85 субъектов РФ. Основные экономические характеристики двух типов социальных инвестиций представлены в Таблице 1.

Таблиия 1

Социальные инвестиции бизнеса и государства, руб.

\begin{tabular}{l|r|r}
\hline \multicolumn{1}{c|}{ Характеристика } & ФНБ (2007-2019 гz.) & ФПГ (2017-2020 гz.) \\
\hline Минимальный грант (заем) & 120000 & 19460 \\
Медианное значение & 2000000 & 1206552 \\
Среднее значение & 2829179 & 2076798 \\
Максимальный грант (заем) & 40000000 & 114989423 \\
Общий объем & & \\
социальных инвестиций & 497935417 & 24431450810 \\
\hline
\end{tabular}

Обе финансовые модели социальных инвестиций достаточно типичны. Они не ориентированы на долговременную поддержку конкретной организации. В случае негосударственных инвестиций речь идет о коротком финансовом импульсе, дающем возможность запустить деятельность или 
повысить ее эффективность, в ситуации государственных грантов- это финансирование отдельного проекта, который должен стать механизмом организационной и финансовой устойчивости.

Непреднамеренным последствием развития системы социальных инвестиций в России становится рост конкуренции между СОНКО и социальными предприятиями - субъектами МСП. Это связано, во-первых, с разной идеологией социального инвестирования со стороны государства и бизнеса. В первом случае это финансирование конкретного проекта, где индикатором успешности становится его реализация и достижение основных целевых показателей. Во втором- это беспроцентный кредит, который должен быть возвращен инвестору, что накладывает большие обязательства и ограничения на социального предпринимателя. Общий объем социальных инвестиций государства в адрес СОНКО значительно превышает инвестиции в развитие социальных предприятий МСП. Вовторых, средний объем социальных инвестиций ограничивает выбор рынков, на которых могут действовать акторы (табл. 2).

Таблица 2

Сравнение направлений проектов СОНКО и деятельности социальных предприятий субъектов МСП

\begin{tabular}{|c|c|c|c|}
\hline \multicolumn{2}{|c|}{$\begin{array}{c}\text { Проектная } \\
\text { деятельность СОНКО }\end{array}$} & \multicolumn{2}{|c|}{$\begin{array}{c}\text { Социальные предприятия } \\
\text { субъектов МСП }\end{array}$} \\
\hline Направление & Процент & Направление & Процент \\
\hline $\begin{array}{l}\text { Охрана здоровья граждан, } \\
\text { пропаганда здорового образа } \\
\text { жизни }\end{array}$ & 15,76 & Образование & 17,91 \\
\hline $\begin{array}{l}\text { Социальное обслуживание, } \\
\text { социальная поддержка } \\
\text { и защита граждан }\end{array}$ & 13,80 & $\begin{array}{l}\text { Социальное } \\
\text { обслуживание } \\
\text { граждан }\end{array}$ & 10,74 \\
\hline $\begin{array}{l}\text { Сохранение } \\
\text { исторической памяти }\end{array}$ & 12,55 & Сфера услуг & 6,89 \\
\hline $\begin{array}{l}\text { Поддержка проектов } \\
\text { в области науки, } \\
\text { образования, просвещения }\end{array}$ & 11,63 & Здравоохранение & 5,51 \\
\hline $\begin{array}{l}\text { Поддержка } \\
\text { проектов в области } \\
\text { культуры и искусства }\end{array}$ & 10,73 & $\begin{array}{l}\text { Культурно-просвети- } \\
\text { тельская деятельность }\end{array}$ & 5,23 \\
\hline
\end{tabular}

В таблице собраны пять направлений (формулировки взяты из документации конкурсов), наиболее подробно представленных в деятельности СОНКО и субъектов МСП, которые практически полностью совпадают. Учитывая ограниченность социальных инвестиций, подобная ситуация не может не влиять на развитие социального бизнеса. Политика российского правительства по развитию социального предпринимательства усиливает 
границы между социальными предприятиями и СОНКО. Ее непреднамеренным последствием становится не только рост конкуренции, но и расширение гибридных форм ведения бизнеса (реализация одного и того же проекта под эгидой субъекта МСП и СОНКО одновременно), усиление противоречий между предпринимательским и некоммерческим сообеетвами.

В завершение проанализируем систему социальных инвестиций в региональном разрезе. Для этого сравним количество победителей конкурса социальных предпринимателей ФНБ и процент СОНКО, получивших грант ФПГ (рис. 1). Точки на рисунке- российские регионы, масштаб точек репрезентирует общий объем займов ФНБ в каждом субъекте РФ. График подтверждает сделанный вывод о конкуренции между социальными предприятиями и СОНКО. Мы видим существование целого пула регионов, где при высоком проценте успешных грантовых заявок количество победителей конкурса социальных предпринимателей малочисленно. Линия тренда, представленная на графике, пусть и не для всех регионов, демонстрирует наличие отрицательной корреляции между успешными СОНКО и субъектами МСП. Объем займов для социальных предприятий так же влияет на снижение числа успешных грантовых заявок СОНКО.

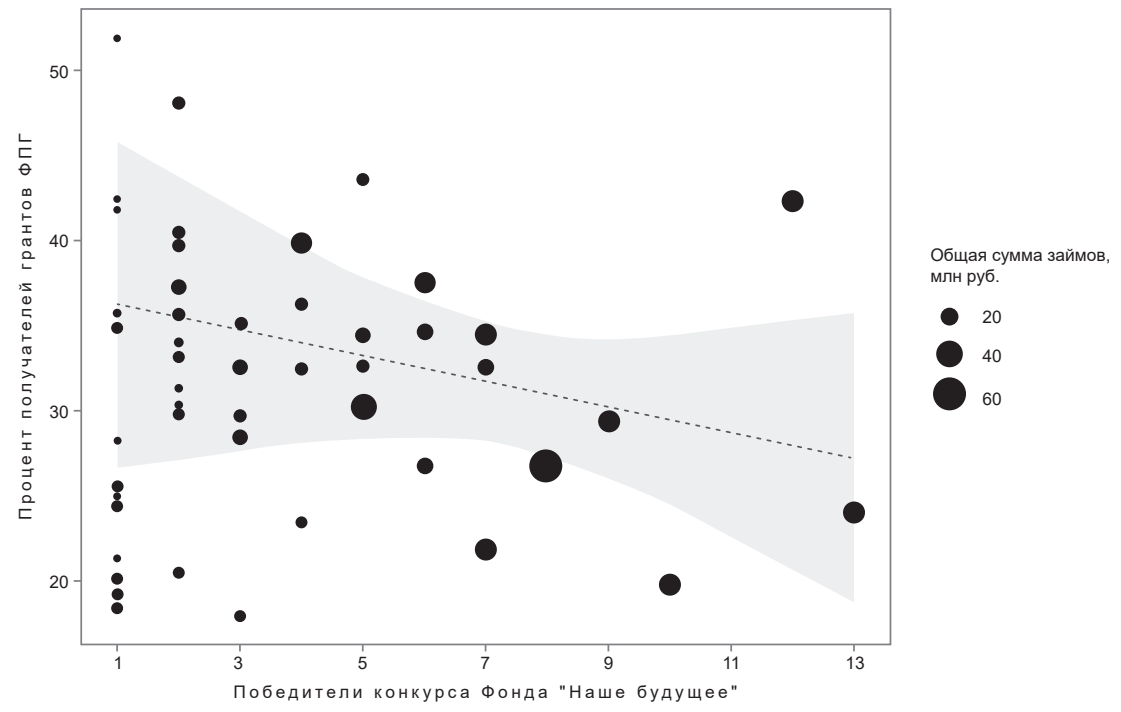

Рисунок 1. Социальные инвестиции Фонда «Наше будущее» и Фонда президентских грантов в разрезе российских регионов

Таким образом, модели развития региональных систем социального предпринимательства во многом определяются степенью активности и развитости либо СОНКО, либо субъектов МСП. Рост конкуренции в региональном разрезе не дает возможности одинаково успешно развиваться 
обоим акторам, что существенно снижает синергетический потенциал региональных систем социального предпринимательства.

\section{Рынок социальных услуг: первый опыт формирования социальных предприятий}

Низкая эффективность государственных социальных инвестиций актуализирует тему диверсификации доходов некоммерческого сектора. Одним из решений проблемы является создание условий для вхождения негосударственных акторов на региональные рынки социальных услуг. Сегодня СОНКО могут получать статус исполнителя общественно полезных услуг в упрощенном порядке (Федеральный закон 2020). Нормативное закрепление статуса социальных предприятий-это такой же упрощенный механизм для субъектов МСП. Рассмотрим рынок негосударственных социальных услуг применительно к российским регионам (рис. 2).

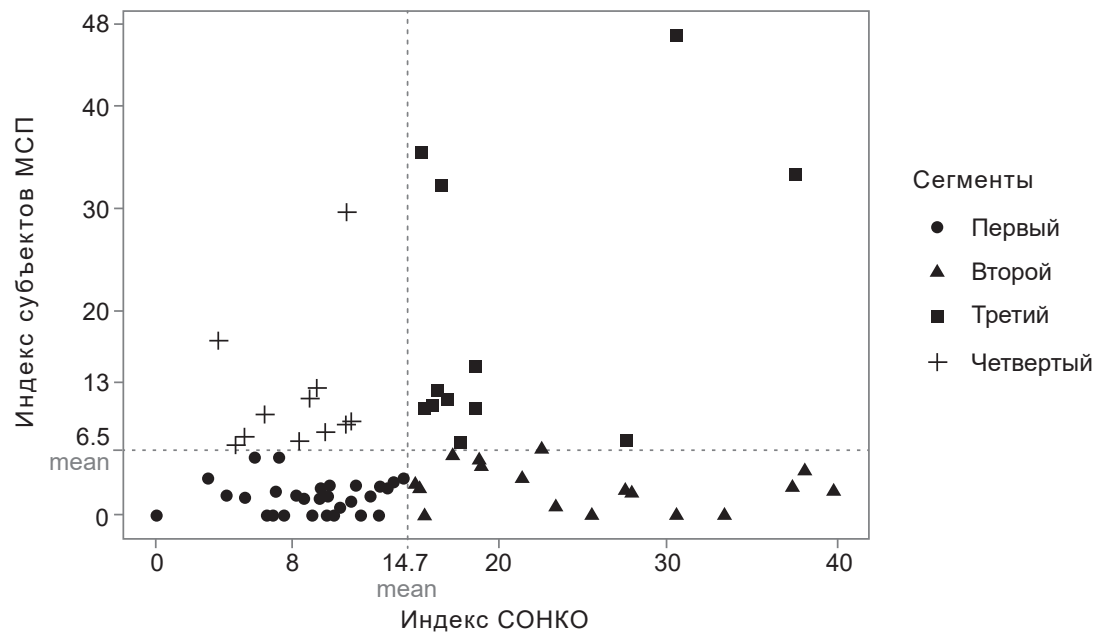

Рисунок 2. Поставщики социальных услуг в российских регионах

Значками обозначены регионы, в которых по-разному выражено соотношение СОНКО и субъектов МСП- поставщиков социальных услуг. Оба индекса (по осям Х и Y) представляют собой отношение числа СОНКО или субъектов МСП, включенных в реестр, к общему числу поставщиков социальных услуг в регионе. Две пунктирные линии демонстрируют средние значения по каждой группе поставщиков, по всем регионам. Среднее число СОНКО по регионам более чем в два раза превышает число субъектов МСП. Мы так же можем наблюдать существование конкуренции на уровне региона между двумя группами поставщиков социальных услуг. 
Тест Манна-Уитни демонстрирует статистически значимые различия между ними. При этом в 14 субъектах РФ нет ни одного бизнеса-поставщика социальных услуг.

На Рисунке 2 имеются 4 сегмента, отличающиеся друг от друга с точки зрения доминирования той или иной группы негосударственных поставщиков социальных услуг. Первый сегмент включает 32 региона, второй17, третий и четвертый- 12 и 11 субъектов РФ соответственно. Первый сегмент характеризуется низкой включенностью негосударственных субъектов в рынок социальных услуг, второй и четвертый-асимметричностью участия СОНКО и МСП в нем. Третий сегмент- это регионы, в которых число негосударственных поставщиков социальных услуг выше средних значений по стране.

Преимущество данного механизма формирования региональных систем социального предпринимательства- в попытке отказаться от секторальных границ и сконцентрироваться на сущности социального предприятия. Развитие региональных рынков социальных услуг- это также возможность повысить их качество и создать условия для конкуренции между поставщиками (Суслова 2014). Большая часть регионов демонстрирует низкую эффективность данного трека. Это связано с неразвитостью институтов поддержки социального бизнеса, стремлением региональных властей сохранить основные сегменты рынка социальных услуг за бюджетными учреждениями, неготовность малого и среднего бизнеса вовлекаться в социальную политику.

\section{Типы систем социального предпринимательства в российских регионах}

Вышесказанное позволяет сформулировать два критерия для типологии российских регионов: уровень развития основных акторов социально-предпринимательского сектора и их пропорции в конкретном регионе. Для типологизации был использован иерархический кластерный анализ, для проверки различий между кластерами- критерий КраскелаУоллиса (табл. 3). В таблице представлены медианные значения каждого признака по регионам, входящим в отдельный кластер, а также уровень значимости теста Краскела-Уоллиса при оценке различий между кластерами по каждому из этих признаков.

Первый кластер включает в себя только один регион-г. Москву. Автор намеренно не удалил столицу при проведении кластерного анализа, чтобы продемонстрировать значительные отличия параметров ее социально-предпринимательской экосистемы от других регионов. Практически все характеристики выражены в Москве значительно сильнее, чем в остальных регионах. Это не говорит о содержательных различиях, скорее, это демонстрация эффекта масштаба, присущего столице. Число негосудар- 
ственных участников рынка социальных услуг в Москве не превышает их число в других регионах, а иногда даже ниже. Это свидетельствует о том, что даже в условиях достаточно развитого московского рынка социальных услуг социальные предприниматели не в состоянии конкурировать с государственными социальными службами и центрами. В то же время число субъектов МСП (22), включенных в рынок социальных услуг, более чем в 1,5 раза превышает число СОНКО (14).

Таблий 3

Результаты кластерного анализа региональных систем социального предпринимательства

\begin{tabular}{|c|c|c|c|c|c|}
\hline \multirow[t]{2}{*}{ Параметр для сравнения } & \multicolumn{4}{|c|}{ Кластеры } & \multirow{2}{*}{ 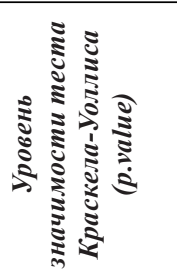 } \\
\hline & 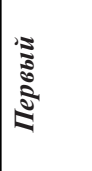 & 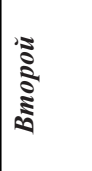 & 离 & 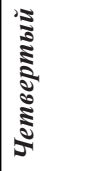 & \\
\hline $\begin{array}{l}\text { Количество победителей конкурса } \\
\text { президентских грантов ФПГ }\end{array}$ & 1625 & 228 & 263 & 78 & 0.000186 \\
\hline $\begin{array}{l}\text { Количество заявок на конкурс } \\
\text { президентских грантов ФПГ }\end{array}$ & 6756 & 663 & 1093 & 245 & 0.000023 \\
\hline $\begin{array}{l}\text { Количество победителей } \\
\text { конкурса социальных } \\
\text { предпринимателей ФНБ }\end{array}$ & 13 & 5 & 4 & 1 & 0.000053 \\
\hline $\begin{array}{l}\text { Количество СОНКО- } \\
\text { поставщиков социальных услуг }\end{array}$ & 14 & 18 & 67 & 7 & 0.001055 \\
\hline $\begin{array}{l}\text { Количество МСП- } \\
\text { поставщиков социальных услуг }\end{array}$ & 22 & 3 & 79 & 2 & 0.000018 \\
\hline $\begin{array}{l}\text { Количество поставщиков } \\
\text { социальных услуг }\end{array}$ & 221 & 111 & 196 & 56 & 0.000094 \\
\hline $\begin{array}{l}\text { Количество } \\
\text { социальных предприятий }\end{array}$ & 76 & 9 & 26 & 2 & 0.014372 \\
\hline
\end{tabular}

Второй кластер-это регионы с высоким уровнем развития некоммерческого сектора и социальных инноваций, что проявляется в самой большой доле успешных грантовых заявок СОНКО (почти $35 \%$ ), а также высоком показателе победителей конкурса социальных проектов ФНБ. Кроме этого, мы видим высокую степень включенности СОНКО в региональные рынки социальных услуг. Этот показатель выше, чем в Москве, и уступает только регионам третьего кластера. Субъекты МСП представлены в реестре поставщиков социальных услуг значительно реже. К данному кластеру относятся Вологодская, Свердловская, Астраханская, Калининградская, Кемеровская, Ростовская, Архангельская, Нижего- 
родская, Волгоградская, Воронежская, Иркутская, Самарская, Новосибирская, Тюменская, Челябинская области, Пермский край, Республика Татарстан, Красноярский край, Алтайский край, Санкт-Петербург и Ленинградская область.

Третий кластер- это регионы с высокоразвитой экосистемой социального предпринимательства. Кластер характеризуется высоким уровнем развития регионов как через механизм социальных инвестиций, так и через участие в реализации государственной социальной политики. Основным отличием данного кластера от других является высокий процент включенности негосударственных организаций в рынок региональных социальных услуг. Более 34 \% поставщиков социальных услуг составляют СОНКО, 40 \% - субъекты МСП. Данный кластер, как и первый, достаточно малочисленный и включает в себя два региона: Ханты-Мансийский автономный округ- Югра и Республику Башкортостан.

Четвертый кластер репрезентирует регионы с низким уровнем развития социально-предпринимательской экосистемы. Представленные признаки здесь значительно ниже, чем в других регионах. Единственное исключение - процент успешных заявок на конкурс президентских грантов для СОНКО. Процент победителей в данном кластере составляет около $32 \%$, что почти на $8 \%$ выше, чем в первом и третьем кластере. Данное обстоятельство во многом связано с зачастую дисфункциональной политикой ФПГ (Смирнов 2020), что, несомненно, снижает эффективность государственных социальных инвестиций. При этом отметим, что регионы данного кластера генерируют меньше всего заявок на конкурсы ФПГ. Процент негосударственных акторов на рынке социальных услуг составляет менее 4 \%. В кластер входят Республика Алтай, Республика Коми, Хабаровский край, Костромская, Курская, Ивановская, Ярославская, Брянская, Владимирская, Кировская, Оренбургская, Рязанская, Томская области, Приморский край, Республика Мордовия, Республика Хакасия, Ямало-Ненецкий автономный округ.

Таким образом, значительная часть российских регионов стратифицирована на две большие группы- с высоким и низким потенциалом социально-предпринимательской экосистемы. Первый и третий кластеры, в которые совокупно входят три субъекта РФ, лишь подтверждают сформулированный выше тезис. Результаты кластеризации в значительной степени совпадают с исследованиями российских социологов, проведенных с применением других методов (Якимец, Никовская 2019). Развитие социального предпринимательства в нашей стране осуществляется в большей степени через инвестирование в некоммерческий сектор и социальные проекты СОНКО, нежели через развитие социальных бизнесов. В большинстве регионов, где идет развитие социального предпринимательства, стратегическая «ставка» в этом вопросе делается именно на некоммерческий сектор. 


\section{Факторы развития социального предпринимательства в российских регионах}

Можно выделить несколько факторов, оказывающих влияние на развитие региональных систем социального предпринимательства. Во-первых, это объем социальных инвестиций. Так, если сравнить средний объем грантов ФПГ (за 2017-2020 гг.) по регионам второго и четвертого кластеров, то в первом случае - это более 336 млн руб., во втором- 124 млн руб. Такая же тенденция наблюдается и по социальным инвестициям бизнеса. Средний объем инвестиций ФНБ в развитие социальных предприятий отдельного региона второго кластера (за весь период существования конкурса) составляет почти 14 млн руб., в то время как для регионов четвертого кластера он равен 3,5 млн руб. Второй фактор- это социально-экономическое развитие региона в целом. Анализ регионов из разных кластеров показывает, что они значимо различаются с точки зрения социально-экономического развития. Медианное значение валового регионального продукта для регионов второго кластера составляет 1191,1 млрд руб., для регионов четвертого кластера387,6 млрд рублей (Росстат 2018). Кроме этого, если посмотреть позиции российских регионов в различных национальных рейтингах, мы можем наблюдать такую же закономерность. Медианное значение рейтинга регионов, входящих во второй кластер, равняется 57, в четвертый- 38,8. Для сравнения: Москва имеет рейтинг 88, регионы третьего кластера- 62,6 (РИА Рейтинг 2019). Наконец, влияние на развитие региональных систем социального предпринимательства оказывает наличие в регионе институтов развития социально-предпринимательских практик. В рамках настоящего исследования в качестве примера рассмотрены центры инноваций социальной сферы (ЦИСС). Важную роль ЦИССов в развитии региональных систем социального предпринимательства отмечают многие российские исследователи (Московская, Климов 2019). Наше исследование также количественно подтверждает их влияние на развитие социального предпринимательства в регионах: 44,4\% регионов второго кластера имеют на свой территории ЦИССы, процент таких регионов в четвертом кластере составляет 17,6.

Таким образом, для развития региональных систем социального предпринимательства необходима эффективная региональная экономика, наличие достаточно большого объема социальных инвестиций, позволяющих социальным акторам развивать свой социальный бизнес и делать проекты устойчивыми, а также эффективные институты поддержки и развития социально-предпринимательских практик.

\section{Заключение}

Формирование региональных систем социального предпринимательства в России носит амбивалентный и противоречивый характер. Государственная 
политика в этой сфере, с одной стороны, ориентирована на вовлечение как можно более широкого спектра негосударственных организаций, с другой, нормативно фиксирует границы между некоммерческим сектором и бизнессообществом. Это обстоятельство приводит к асимметричности региональных систем социального предпринимательства: в ряде случаев их развитие происходит за счет СОНКО, в других - за счет субъектов МСП. Учитывая ограниченный объем социальных инвестиций, данная стратегия является явно деструктивной с точки зрения развития социально-предпринимательских практик в субъектах РФ. Сегодня лишь незначительное число российских территорий выстраивает интеграционную политику, основа которойсоздание условий для равноценного развития СОНКО и МСП как акторов социального предпринимательства. Асимметричность усиливается за счет разного объема и характера социальных инвестиций в развитие СОНКО и субъектов МСП (гранты, выделяемые СОНКО, являются невозвратными, в отличие от беспроцентных займов и субсидий для МСП, при этом их совокупный объем значительно больше).

Разный уровень государственной поддержки СОНКО и субъектов МСП, с одной стороны, и стремление вывести их на один рынок, с другой, приводят к росту конкуренции между ними. Это усиливает асимметричность региональных систем и ведет к воспроизводству их дисфункциональности. Вместо расширения конкуренции с государственными поставщиками социальных услуг, что, в свою очередь, должно приводить к повышению их качества, негосударственные акторы вынуждены конкурировать между собой на небольших региональных рынках за ограниченные социальные инвестиции. При этом они изначально находятся в менее выгодном положении, чем государственные и муниципальные социальные учреждения. В результате не происходит ни повышения качества социальных услуг, ни широкого распространения эффективных социально-предпринимательских практик, способных повлиять на качество жизни жителей российских территорий.

Проведенный анализ позволил выделить четыре типа региональных систем социального предпринимательства. Характерной чертой первого типа является активное развитие некоммерческого сектора как потенциального производителя инноваций и широкое распространение социальных предприятий, созданных субъектами МСП. Это интеграционная модель, предполагающая синергетическое развитие СОНКО и МСП, которая сегодня реализуется только в столице. Еще один тип связан с развитием региональных рынков социальных услуг населению. Это также интеграционный подход, позволяющий и СОНКО, и субъектам МСП стать акторами социального предпринимательства посредством единого социального механизма (статус поставщика социальных услуг), независимо от их организационноправовой формы. Это достаточно перспективная модель развития социального предпринимательства в регионах, которая на сегодняшний день реализуется 
только в двух субъектах РФ. Большинство же российских регионов разделены на два типа с точки зрения развития социального предпринимательства. К первому относятся субъекты РФ, в которых социально-предпринимательские практики практически не развиты, ко второму- регионы, имеющие опыт и потенциал для их расширения, главным образом за счет эффективно работающих СОНКО. Значительное число региональных систем находятся сегодня в стадии своего становления, что, несомненно, тормозит процесс развития социального предпринимательства в России.

В этом контексте важно выявить факторы, влияющие на эффективность региональных систем социального предпринимательства. Наиболее значимые из них - социально-экономическое положение региона в целом, уровень социальных инвестиций, наличие и эффективность институтов поддержки и развития социального предпринимательства. Если первые два в меньшей мере зависят от региональной власти, последний, наоборот, является наиболее реализуемым в краткосрочной перспективе. Проведенное исследование демонстрирует, что в России сегодня практически нет институтов сопровождения транзита СОНКО и субъектов МСП в сектор социального предпринимательства. Обе группы акторов в случае самоопределения в качестве социальных предпринимателей вынуждены действовать самостоятельно, часто не имея необходимых компетенций для этого. В этой ситуации расширение спектра региональных институтов поддержки социального предпринимательства может стать эффективным механизмом его развития.

\section{Выражение признательности}

Редакция благодарит программу Университетское партнерство за поддержку и возможность опубликовать данную статью.

\section{Список источников}

Албутова А.И. (2013) Социальное предпринимательство в России: ключевые игроки и потенциал формирования. Экономическая социология, 14 (3): 109-132.

Арай Ю.Н. (2018) Бизнес-модели в социальном предпринимательстве: подход к построению типологии. Российский журнал менеджмента, 16 (2): 253-272.

Баталина М., Московская А., Тарадина Л. (2007) Обзор опыта и концепций соичильного предпринимательства с учетом возможностей его применения в современной России. Препринт серии «Институциональные проблемы российской экономики» WP-1/2008/02. М.: ВШЭ.

Баханькова Е.Р., Москвина А. Ю., Суходольская Н. А., Чупрова К. Г. (ред.) (2013) Предпринимательская деятельность НКО. СПб.

Борнштейн Д. (2012) Как изменить мир. Социальное предпринимательство и сила новых идей. М.: Альпина Паблишер. 
Кикал Дж. (2014) Социальное предпринимательство: миссия-сделать мир лучше. М.: Альпина Паблишер.

Московская А., Климов И. (2019) Как сделать ЦИССы эффективным инструментом развития социального предпринимательства в регионах? Мир соииального предпринимательства, (3): 3-5.

Недялкова А. (2016) Социальное предпринимательство в современной России: как сочетать создание социальной пользы и обеспечение финансовой устойчивости? Вестник общественного мнения, 122 (3-4): 109-129.

Новый бизнес (2020) Карта соичальных предпринимателей. Доступно по ссылке: http://nb-forum.ru/geography?region=AS (дата обращения: 10 марта 2020).

Проекты ФНБ (2020) Фонд региональных соичальных программ «Наме будущее». Доступно по ссылке: http://www.nb-fund.ru/projects/ (дата обращения: 10 марта 2020).

Проекты ФПГ (2020) Проекты Фонда президентских грантов. Доступно по ссылке: https://президентскиегранты.pф/public/application/cards (дата обращения: 10 марта 2020).

РИА Рейтинг (2019) Рейтинг соииально-экономического положения регионов- 2019. Доступно по ссылке: https://riarating.ru/infografika/20190604/630126280.html (дата обращения: 03 апреля 2020).

Росстат (2018) Валовый региональный продукт. Доступно по ссылке: https://www. gks.ru/search?q=валовый+региональный+продукт (дата обращения: 03 апреля 2020).

Сакоян А. (2012) Социальное предпринимательство. Доступно по ссылке: http:// polit.ru/article/2012/03/23/Kerlin/ (дата обращения: 10 марта 2020).

Смирнов В. А. (2020) Эффективность грантовой поддержки российских социально ориентированных некоммерческих организаций (на примере Фонда президентских грантов). Социологические исследования, (9): 79-89.

Суслова С.В. (2014) Некоммерческие производители на региональных квазирынках социальных услуг. Вопросы государственного и муниципального управления, (3): 72-89.

Федеральный закон (2013) Об основах социального обслуживания граждан Российской Федерации, № 442-ФЗ от 28.12.2013.

Федеральный закон (2019) О внесении изменений в Федеральный закон «О развитии малого и среднего предпринимательства в Российской Федерации», № 245-Ф3 от 26.07.2019.

Федеральный закон (2020) О внесении изменений в статьи 2 и 31.4 Федерального закона «О некоммерческих организациях», № 60-ФЗ от 18.03.2020.

ЦИРКОН (2013) Портрет сочиального предпринимателя: ключевые характеристики. Доступно по ссылке: http://www.zircon.ru/upload/iblock/e4e/Portret_SP_Otchet. pdf (дата обращения: 10 марта 2020).

Якимец В.Н., Никовская Л.И. (2019) Поддержка социального предпринимательства: оценка механизмов и рейтинг регионов России. Социологические исследования, (5): 99-109. 
Anderson B., Dees G. (2008) Rhetoric, Reality, and Research: Building a Solid Foundation for the Practice of Social Entrepreneurship. In: A. Nicholls (ed.) Social EntrepreneurshipNew Models of Sustainable Social Change. Oxford: Oxford University Press: 80-144.

Bacq S., Janssen F. (2011) The Multiple Faces of Social Entrepreneurship: A Review of Definitional Issues Based on Geographical and Thematic Criteria. Entrepreneurship \& Regional Development, 23 (5-6):373-403.

Chell E. (2007) Social Enterprise and Entrepreneurship - Towards a Convergent Theory of the Entrepreneurial Process. International Small Business Journal, (1): 5-26.

Dees G. (1998) Enterprising Non-profits. Harvard Business Review, (1): 54-66.

Github (2020) JSPS. Available at: https://github.com/kanoigt/JSPS (accessed 10 March 2020).

Nicholls A. (2008) Social Entrepreneurship: New Models of Sustainable Social Change. Oxford: Oxford University Press.

OECD (2015) Social Impact Investment: Building the Evidence Base. Available at: https://doi.org/10.1787/9789264233430-en (accessed 10 March 2020).

Simms S. V.K., Robinson J. A. (2008) Activist or Entrepreneur?: An Identity-based Model of Social Entrepreneurship. In: J. A. Robinson, J. Mair, K. Hockerts (eds.) International Perspectives on Social Entrepreneurship. Basingstoke: Palgrave: 9-26. 
Vladimir Smirnov

\title{
REGIONAL SYSTEMS OF SOCIAL ENTREPRENEURSHIP IN RUSSIA: TYPOLOGY, DEVELOPMENT FACTORS AND KEY CONTRADICTIONS
}

\begin{abstract}
In Russia over the last decade, the discourse around social entrepreneurship, has been updated to be based on issues of more effective solutions of social problems. The main actors are socially-oriented non-profit organizations, small and medium-sized businesses. There are three mechanisms in the institutionalization of social entrepreneurship in Russia. The first is related to the development of a system of social investment. The second is the attempt of the government to include non-governmental organizations in the system of state social policy. The third mechanism regards the legal status of small and medium-sized socially-oriented businesses as a social enterprise. The article analyzes the implementation of the first two mechanisms. Due to the uneven development of Russian regions, the specific features of each region should be taken into account. Based on a cluster analysis, the article provides a typology of Russian regions in the terms of the development of regional socio-entrepreneurial systems. We conclude a market of social and entrepreneurial services as a competitive field for socially-oriented non-profit organizations and small and medium-sized businesses has emerged. The low level of development of social and entrepreneurial practices in Russia is explained by the influence of three main factors: the socio-economic development of a particular region, the level of social investment, and the availability and effectiveness of social entrepreneurship support institutions. The article identifies a number of unintended consequences of state policy, hindering the development of social entrepreneurship in Russia. The most significant of these are the strengthening of intersectoral borders between the non-profit sector and the business community, reducing the motivation of entrepreneurs to develop social and entrepreneurial practices, and the dominance of budget organizations in the social services market.
\end{abstract}

Keywords: regional systems of social entrepreneurship, socially-oriented non-profit organizations, small and medium-sized businesses, social service providers

DOI: $10.17323 / 727-0634-2021-19-1-23-40$

\section{Referens:}

Albutova A.I. (2013) Sotsial'noe predprinimatel'stvo v Rossii: klyuchevye igroki i potentsial formirovaniya [Social Entrepreneurship in Russia: Key Actors and Development Potential]. Ekonomicheskaya sotsiologiya [Economic Sociology], 14 (3): 109-132.

Vladimir A. Smirnov- Dr. Sci. (Soc.), associate Professor, Vice-rector for strategic communications, Kostroma state University, Kostroma, Russian Federation. Email: kano_igt@mail.ru 
Anderson B., Dees G. (2008) Rhetoric, Reality, and Research: Building a Solid Foundation for the Practice of Social Entrepreneurship. In: A. Nicholls (ed.) Social EntrepreneurshipNew Models of Sustainable Social Change. Oxford: Oxford University Press: 80-144.

Araj Ju.N. (2018) Biznes-modeli v social'nom predprinimatel'stve: podhod k postroeniju tipologii [Business Models in Social Entrepreneurship: An Approach to Building a Typology]. Rossijskij zhurnal menedzhmenta [Russian Journal of Management], 16 (2):253-272.

Bacq S., Janssen F. (2011) The Multiple Faces of Social Entrepreneurship: A Review of Definitional Issues Based on Geographical and Thematic Criteria. Entrepreneurship \& Regional Development, 23 (5-6):373-403.

Bahan'kova E.R., Moskvina A. Ju., Suhodol'skaja N.A., Chuprova K. G. (eds.) (2013) Predprinimatel'skaja dejatel'nost' $N K O$ [Entrepreneurial Activities of NGOs]. Saint Petersburg.

Batalina M., Moskovskaja A., Taradina L. (2007) Obzor opyta i koncepcij social'nogo predprinimatel'stva s uchetom vozmozhnostej ego primenenija $v$ sovremennoj Rossii [Review of the Experience and Concepts of Social Entrepreneurship, Taking into Account the Possibilities of its Application in Modern Russia]. Preprint of the series 'Institutional problems of the Russian Economy' WP-1/2008/02. Moscow: HSE.

Bornshtejn D. (2012) Kak izmenit' mir. Social'noe predprinimatel'stvo i sila novyh idej [How to Change the World. Social Entrepreneurship and the Power of New Ideas]. Moscow: Al'pina Pablisher.

Chell E. (2007) Social Enterprise and Entrepreneurship - Towards a Convergent Theory of the Entrepreneurial Process. International Small Business Journal, (1): 5-26.

Dees G. (1998) Enterprising Non-profits. Harvard Business Review, (1): 54-66.

Federal Law (2013) Ob osnovah social'nogo obsluzhivanija grazhdan Rossijskoj Federacii [On the Basics of Social Services for Citizens of the Russian Federation] N 442-FZ from 28.12.2013.

Federal Law (2019) O vnesenii izmenenij v Federal'nyj zakon 'O razvitii malogo i srednego predprinimatel'stva $v$ Rossijskoj Federacii' [On Amendments to the Federal Law 'On the Development of Small and Medium-Sized Businesses in the Russian Federation'] N 245-FZ from 26.07.2019.

Federal Law (2020) O vnesenii izmenenij v stat'i 2 i 31.4 Federal'nogo zakona 'O nekommercheskih organizacijah' [About Modification of Articles 2 and 31.4 of the Federal Law 'On Non-commercial Organizations'] N 60-FZ from 18.03.2020.

FOF projects (2020) Fond regional'nyh social'nyh programm 'Nashe budushhee' [Fund for Regional Social Programs 'Our Future']. Available at: http://www.nb-fund.ru/projects/ (accessed 10 March 2020).

Github (2020) JSPS. Available at: https:/github.com/kanoigt/JSPS (accessed 10 March 2020).

Kikal Dzh. (2014) Social'noe predprinimatel'stvo: missija-sdelat' mir luchshe [Social Entrepreneurship: Mission- To Make the World a Better Place]. M.: Al'pina Pablisher.

Moskovskaja A., Klimov I. (2019) Kak sdelat' CISSy jeffektivnym instrumentom razvitija social'nogo predprinimatel'stva v regionah? [How to Make Cissy an Effective Tool for the Development of Social Entrepreneurship in the Regions?]. Mir social'nogo predprinimatel'stva [The World of Social Entrepreneurship], (3):3-5. 
Nedjalkova A. (2016) Social'noe predprinimatel'stvo v sovremennoj Rossii: kak sochetat' sozdanie social'noj pol'zy i obespechenie finansovoj ustojchivosti? [Social Entrepreneurship in Modern Russia: How to Combine the Creation of Social Benefits while Ensuring Financial Stability?] Vestnik obshhestvennogo mnenija [Bulletin of Public Opinion], 122 (3-4): 109-129.

New business (2020) Karta social'nyh predprinimatelej [Map of Social Entrepreneurs]. Available at: http://nb-forum.ru/geography?region=AS (accessed 10 March 2020).

Nicholls A. (2008) Social Entrepreneurship: New Models of Sustainable Social Change. Oxford: Oxford University Press.

OECD (2015) Social Impact Investment: Building the Evidence Base. Available at: https://doi.org/10.1787/9789264233430-en (accessed 10 March 2020).

PGF project (2020) Proekty Fonda prezidentskih grantov [Projects of the Presidential Grants Fund]. Available at: https://prezidentskiegranty.rf/public/application/cards (accessed 10 March 2020).

RIA rating (2019) Rejting social'no-jekonomicheskogo polozhenija regionov- 2019 [Rating of Socio-economic Status of Regions-2019]. Available at: https://riarating.ru/infografika/20190604/630126280.html (accessed 3 April 2020).

Rosstat (2018) Valovyj regional'nyj produkt [Gross Regional Product]. Available at: https:// www.gks.ru/search?q=valovyj+regional'nyj+produkt (accessed 3 April 2020).

Sakojan A. (2012) Social'noe predprinimatel'stvo [Social Entrepreneurship]. Available at: http://polit.ru/article/2012/03/23/Kerlin/ (accessed 10 March 2020).

Simms S. V.K., Robinson J. A. (2008) Activist or Entrepreneur?: An Identity-based Model of Social Entrepreneurship. In: J. A. Robinson, J. Mair, K. Hockerts (eds.) International Perspectives on Social Entrepreneurship. Basingstoke: Palgrave: 9-26.

Smirnov V. A. (2020) Jeffektivnost' grantovoj podderzhki rossijskih social'no-orientirovannyh nekommercheskih organizacij (na primere Fonda prezidentskih grantov) [Effectiveness of Grant Support for Russian Socially-oriented Non-profit Organizations (the Case of the Presidential Grants Fundation)]. Sociologicheskie issledovanija [Sociological Studies], (9): 79-89.

Suslova S. V. (2014) Nekommercheskie proizvoditeli na regional'nyh kvazirynkah social'nyh uslug [Nonprofit Providers on Regional Social Service Qausi-market]. Voprosy gosudarstvennogo i municipal'nogo upravleniya [Public Administration Issues], (3): 72-89.

TSIRKON (2013) Portret social'nogo predprinimatelja: kljuchevye harakteristiki [Portrait of a Social Entrepreneur: Key Characteristics]. Available at: http://www.zircon.ru/ upload/iblock/e4e/Portret_SP_Otchet.pdf (accessed 10 March 2020).

Yakimec V.N., Nikovskaya L. I. (2019) Podderzhka social'nogo predprinimatel'stva: ocenka mekhanizmov i rejting regionov Rossii [Support of Social Entrepreneurship: An Evaluation of Mechanisms and Rating of Russian]. Sotsiologicheskie Issledovaniia [Sociological Studies], (5): 99-109. 